\title{
Características da Carcaça e da Carne de Novilhos e de Vacas de Descarte Hereford, Terminados em Confinamento
}

\author{
Fabiano Nunes Vaz ${ }^{1}$, João Restle ${ }^{2}$, Arlei Rodrigues Bonnet de Quadros ${ }^{3}$, Leonir Luiz Pascoal ${ }^{3}$, \\ Luis Maria Bonnecarrère Sanchez ${ }^{4}$, Joilmaro Rodrigo Pereira Rosa ${ }^{5}$, \\ Luis Fernando Glasenapp de Menezes $^{6}$
}

\begin{abstract}
RESUMO - Objetivou-se estudar os aspectos quantitativos e qualitativos da carcaça e da carne de doze animais de duas categorias de bovinos Hereford, novilhos de dois anos de idade e vacas de descarte com idade média de oito anos, tomados ao acaso do mesmo rebanho, os quais foram terminados por 112 dias em confinamento, sendo que na primeira fase de 56 dias a relação volumoso (cana-de-açúcar triturada) : concentrado foi de $69: 31$ e na segunda fase, de $57: 43$. As vacas apresentaram maiores pesos de abate $(475,7 \mathrm{vs} .426,7 \mathrm{~kg})$ e porcentagem de costilhar (15,28 vs. 14,20\%), porém rendimentos de carcaça fria (46,62 vs. 49,14\%) inferiores. Não ocorreu diferença significativa entre as categorias para peso de carcaça fria. Os novilhos apresentaram melhores conformação de carcaça ("boa menos" vs. “regular”) e perímetro de braço (34,67 vs. $33,58 \mathrm{~cm})$, com menor comprimento de carcaça (121,9 vs. 131,6 cm) do que as vacas. A área de Longissimus dorsi foi maior nos novilhos $\left(54,52 \mathrm{~cm}^{2}\right)$ do que nas vacas $\left(48,72 \mathrm{~cm}^{2}\right)$, assim como a porcentagem de músculo na carcaça $(63,96$ vs. $56,28 \%)$. As vacas de descarte apresentaram maior percentagem de gordura na carcaça $(25,29$ vs. $21,08 \%)$ e de marmoreio na carne ("pequeno menos" vs. "leve menos"). Os novilhos apresentaram carne mais suculenta (5,45 vs. 4,70 pontos), de melhor palatabilidade ( 5,60 vs. 4,83 pontos) e mais macia ( 5,15 vs. 4,12 pontos) do que as vacas, mas não houve diferença significativa na força para cizalhamento das fibras da carne. A carne das vacas mostrou maior quebra ao cozimento $(33,94 \%)$ do que a carne de novilhos $(31,55 \%)$. Os resultados deste trabalho mostraram que os novilhos abatidos com dois anos de idade produzem carcaças mais magras e carne de melhor qualidade que vacas de descarte.
\end{abstract}

Palavras-chave: Bos taurus, categorias, fêmeas de descarte, maciez, marmoreio

\section{Study of the Carcass and Meat of Hereford Steers and Cull Cows, Feedlot Finished}

\begin{abstract}
This work was conducted with the objective to study the quantitative and qualitative traits of carcass and meat of two Hereford categories, two years old steers and cull cows with average age of eight years. Twelve animals of each categorie were randomly taken from the same herd, and feedlot finished during a 112 days period, being the roughage (sugar cane) : concentrate ratio of $69: 31$ during the first phase of 56 days and $57: 43$ during the second phase. Slaughter weight was higher for cows (475.7 vs. 426.7 $\mathrm{kg}$ ), as well as the sidecut percentage (15.28 vs. $14.20 \%$ ), but cows showed lower cold dressing percentage (46.62 vs. $49.14 \%$ ). No significant difference between categories was observed for cold carcass weight. The steers showed higher carcass conformation score ("good"-vs. "regular") and arm perimeter ( $34.67 \mathrm{vs.} 33.58 \mathrm{~cm})$, but lower carcass length ( $121.9 \mathrm{vs.} 131.6 \mathrm{~cm})$ than the cows. Longissumus dorsi area was higher for the steers $\left(54.52 \mathrm{~cm}^{2}\right)$ than for the cows $\left(48.72 \mathrm{~cm}^{2}\right)$, as well as the carcass muscle percentage (63.96 vs. $\left.56.28 \%\right)$, but the cull cows showed higher carcass fat percentage (25.29 vs. $21.08 \%$ ) and marbling score ("small" - vs. "light -"). Meat from the steers was more juicy ( 5.45 vs. 4.70 points), had better flavor ( 5.60 vs. 4.83 points) and was more tender ( 5.15 vs. 4.12 points) than meat from the cows. However, no significant difference in the Shear value was observed between the two categories. Meat of the cows showed higher cooking loss (33.94\%) than meat from the steers $(31.55 \%)$. The results of this work showed that the steers slaughtered with two years of age, produce leaner carcasses and meat of better quality than cull cows.
\end{abstract}

Key Words: Bos taurus, categories, cull females, marbling, tenderness

\section{Introdução}

O aumento do consumo de carne bovina passa pelo incentivo ao abate de animais jovens, visando melhorar a qualidade da carne ofertada no mercado (Vaz \& Restle, 1998). No entanto, nos últimos anos, a melhoria das técnicas de produção bovina vêm aumentando consideravelmente a produção de be-

1 Zootecnista, MS, Progepec Consultores Associados Ltda. E-mail: fnvaz@terra.com.br

2 Engenheiro-Agrônomo, PhD, Pesquisador do CNPq. Professor Titular do Departamento de Zootecnia da UFSM. Campus Camobi, Santa Maria - RS, CEP 97119-105. E.mail: jorestle@ccr.ufsm.br

3 Zootecnista, MS, Professor Assistente do Departamento de Zootecnia da UFSM.

${ }^{4}$ Engenheiro-Agrônomo, PhD, Professor do Departamento de Zootecnia da UFSM.

5 Engenheiro-Agrônomo, Aluno do curso de Mestrado em Zootecnia da UFSM.

${ }^{6}$ Acadêmico do curso de Zootecnia da UFSM. 
zerros, oferecendo não somente maior número de machos para abate, mas também aumentando o número de novilhas para a reposição dos ventres, oferecendo ao produtor a opção de ser mais rígido na pressão de seleção sobre as fêmeas de cria, além de grande quantidade de fêmeas de descarte adultas para os frigoríficos.

Nos países desenvolvidos, a carne de novilhos é basicamente comercializada e consumida após o resfriamento, ao passo que a carne de vacas de descarte, em grande parte, é processada e industrializada. Em razão de alguns importantes países exportadores e importadores de carne estarem com os rebanhos bastante afetados por problemas ligados à doenças infecto-contagiosas, é esperado um vazio na oferta de carne bovina no mercado mundial, candidatando o Brasil como produtor e exportador potencial de carne, por intermédio do abate de novilhos e vacas de descarte, em que não somente a carne in natura, mas também a carne industrializada, deve aumentar as suas demandas (Anualpec, 2000).

Estudando as características qualitativas da carcaça de novilhos de 2,5 anos e vacas de descarte Charolês, Townsend et al. (1990c) não observaram diferença significativa entre as duas categorias para as características textura, marmoreio e força de cizalhamento para romper as fibras da carne.

Já com relação à porcentagem de músculo na carcaça, Townsend et al. (1990c) verificaram que a porcentagem de músculo na carcaça foi semelhante para as duas categorias estudadas, sendo que os novilhos apresentaram 68,3\% de músculo e as vacas, $64,9 \%$. Vaz et al. (2001c) utilizaram vacas de descarte abatidas com diferentes idades, concluindo que a porcentagem de músculo na carcaça diminuiu, à medida que aumentou a idade das vacas, comportamento contrário ao verificado com a porcentagem de gordura, a qual foi mais alta nas vacas abatidas com mais idade.

Analisando o efeito da idade de machos castrados da raça Brangus, Del Duca et al. (1999) observaram $3,6 \mathrm{~mm}$ de gordura sobre a carcaça de animais abatidos aos 27 meses de idade, e 6,2 $\mathrm{mm}$ em carcaças de bovinos abatidos com 41 meses. Também verificando o efeito da idade ao abate, Restle et al. (2000c) utilizaram fêmeas de descarte abatidas em diferentes idades, constatando que a espessura de gordura sobre a carcaça foi maior, à medida que aumentou a idade ao abate, ou seja, de 2,$22 ; 2,47$; 3,59 ; e 3,69 mm, para vacas com, respectivamente, 4 , 5-6, 7-8 e mais de oito anos de idade ao abate.
Trabalhando com fêmeas de descarte abatidas em diferentes idades, Restle et al. (2000a) verificaram que vacas com idade variando entre sete e oito anos obtiveram maior peso de abate do que vacas com quatro anos de idade (453 kg vs. $416 \mathrm{~kg}$ ). Ao compararem novilhas de três anos com vacas de descarte com idade média de oito anos de idade, Restle et al. (2001) verificaram maior rendimento de carcaça e de corte serrote nas novilhas, sendo a porcentagem de costilhar maior nas vacas adultas.

O objetivo deste trabalho foi comparar as características de carcaça e da carne de novilhos da raça Hereford de dois anos de idade e de vacas de descarte da mesma raça, abatidas com idade média de oito anos.

\section{Material e Métodos}

Este trabalho foi conduzido no Setor de Bovinocultura de Corte do Departamento de Zootecnia da Universidade Federal de Santa Maria, situada na Depressão Central do Rio Grande do Sul. Foram tomados ao acaso de um rebanho Hereford de uma propriedade particular, dois lotes de doze animais, um de vacas de descarte com idade média de oito anos de idade, e outro de novilhos de 20 meses de idade.

Os animais foram alimentados durante 112 dias, sendo que na primeira fase (56 dias) a relação volumoso (cana-de-açúcar triturada) : concentrado foi de $69: 31$ e na segunda fase, de $57: 43$. O teor de proteína bruta na dieta dos novilhos foi de $12,4 \%$ e nas vacas de descarte, de 10,4\%.

Os animais foram abatidos na mesma data, e o peso de fazenda dos animais foi tomado antes do embarque para o frigorífico, observando-se um jejum de sólidos de 12 horas. O abate ocorreu em matadouro comercial, seguindo-se o fluxo normal do estabelecimento. Após o abate, as carcaças foram lavadas e identificadas antes de entrar para a câmara de resfriamento.

Decorridas 24 horas de resfriamento a uma temperatura de $-2^{\circ} \mathrm{C}$, foi medido o peso de carcaça fria, em seguida, a conformação de carcaça foi medida subjetivamente seguindo-se uma escala de um a dezoito pontos, onde o maior valor indica melhor conformação. A maturidade fisiológica da carcaça foi medida também subjetivamente através da observação do grau de ossificação das apófises espinhosas das vértebras torácicas e fusionamento das vértebras sacrais, em que os valores mais baixos da escala de 
quinze pontos indicam maturidade fisiológica mais avançada. As medidas de comprimento de carcaça, de perna, de braço, espessura de coxão e perímetro de braço, que indicam o desenvolvimento corporal, seguiram a metodologia sugerida por Muller (1987).

As porcentagens dos cortes dianteiro, costilhar e serrote foram realizadas através da separação destes cortes, pesagem e posterior cálculo da porcentagem destes em relação ao peso da meia-carcaça fria. A área de Longissimus dorsi foi medida na altura da $12^{\mathrm{a}}$ costela, onde mensurou-se a área desse músculo realizando-se um corte perpendicular ao comprimento do mesmo. Também nesse mesmo corte foi mensurada a espessura de gordura sobre a carcaça.

A avaliação das características cor, textura e marmoreio da carne, foram realizadas no músculo Longissimus dorsi, na altura da $12^{\mathrm{a}}$ costela, conforme a técnica descrita por Muller (1987). Para a determinação da composição física da carcaça foi utilizada a técnica de Hankins \& Howe (1946), sendo que a porção de Longissimus dorsi extraída da amostra usada nessa técnica, foi embalada, identificada e congelada para posterior cálculo das quebras ao descongelamento e à cocção, e também análise da maciez, palatabilidade e suculência, conforme a técnica descrita por Muller (1987). A mesma amostra foi usada para medir a força necessária para o corte perpendicular das fibras, por intermédio do aparelho WB-Shear.

O delineamento experimental foi o inteiramente casualizado e os resultados foram processados por intermédio do pacote estatístico SAS (1990), que submeteu os dados à análise de variância e "Teste F", em nível de significância de 5\%.

\section{Resultados e Discussão}

Constam na Tabela 1 os resultados referentes aos pesos de abate e carcaça fria, rendimento de carcaça fria, espessura de gordura, peso e porcentagem dos cortes comerciais da carcaça das duas categorias estudadas. Observa-se que o peso de abate foi maior $(\mathrm{P}<0,0006)$ nas vacas de descarte $(475,7 \mathrm{~kg})$ do que nos novilhos (426,7 kg). Restle et al. (2001), ao verificarem que novilhas Charolês abatidas aos três anos de idade apresentaram menor peso de abate do que vacas de descarte da mesma raça, concluíram que as novilhas não haviam completado o seu crescimento, o que foi confirmado pelo menor comprimento de carcaça desses animais. Restle et al. (2000a), trabalhando com vacas de descarte terminadas com suplementação energética em pastagem cultivada de

Tabela 1 - Médias de peso de abate, de carcaça, rendimento de carcaça, espessura de gordura e percentagem dos cortes comerciais

Table 1 - Means for slaughter weight, carcass weight, dressing percentage, fat thickness and commercial cuts percentages

\begin{tabular}{|c|c|c|c|c|}
\hline $\begin{array}{l}\text { Característica } \\
\text { Characteristic }\end{array}$ & $\begin{array}{c}\text { Novilhos } \\
\text { Steers }\end{array}$ & $\begin{array}{l}\text { Vacas } \\
\text { Cows }\end{array}$ & $\begin{array}{l}\text { Erro-pradrão } \\
\text { Standard error }\end{array}$ & $\begin{array}{c}\text { Probabilidade } \\
\text { Probability }\end{array}$ \\
\hline $\begin{array}{l}\text { Peso de abate, } \mathrm{kg} \\
\text { Slaughter weight, } \mathrm{kg}\end{array}$ & 426,7 & 475,7 & 8,6 & 0,0006 \\
\hline $\begin{array}{l}\text { Peso de carcaça fria, } \mathrm{kg} \\
\text { Cold carcass weight, } \mathrm{kg}\end{array}$ & 209,7 & 221,7 & 4,3 & 0,0617 \\
\hline $\begin{array}{l}\text { Rendimento de carcaça fria, \% } \\
\text { Dressing percentage }\end{array}$ & 49,14 & 46,62 & 0,42 & 0,0003 \\
\hline $\begin{array}{l}\text { Espessura de gordura, } \mathrm{mm} \\
\text { Fat thickness, } \mathrm{mm}\end{array}$ & 5,33 & 5,83 & 0,57 & 0,5404 \\
\hline $\begin{array}{l}\text { Dianteiro, } \mathrm{kg} \\
\text { Forequarter, } \mathrm{kg}\end{array}$ & 38,75 & 40,33 & 0,90 & 0,2277 \\
\hline $\begin{array}{l}\text { Dianteiro, } \% \\
\text { Forequarter percentage }\end{array}$ & 36,96 & 36,36 & 0,28 & 0,1649 \\
\hline $\begin{array}{l}\text { Costilhar, } \mathrm{kg} \\
\text { Sidecut, } \mathrm{kg}\end{array}$ & 14,92 & 16,92 & 0,41 & 0,0022 \\
\hline $\begin{array}{l}\text { Costilhar, } \% \\
\text { Sidecutpercentage }\end{array}$ & 14,20 & 15,28 & 0,24 & 0,0034 \\
\hline $\begin{array}{l}\text { Serrote, } \mathrm{kg} \\
\text { Sawcut, } \mathrm{kg}\end{array}$ & 51,33 & 53,83 & 1,11 & 0,1261 \\
\hline $\begin{array}{l}\text { Serrote, } \% \\
\text { Sawcutpercentage }\end{array}$ & 48,98 & 48,54 & 0,34 & 0,3665 \\
\hline
\end{tabular}

R. Bras. Zootec., v.31, n.3, p.1501-1510, 2002 (suplemento) 
estação fria, constataram que vacas com idade variando entre sete e oito anos obtiveram maior peso de abate (453 kg) do que vacas com quatro anos de idade $(416 \mathrm{~kg})$.

Embora as vacas tenham sido $49 \mathrm{~kg}$ mais pesadas que os novilhos ao abate, o maior rendimento de carcaça dos novilhos $(\mathrm{P}<0,0003)$ fez com que não houvesse diferença significativa entre as duas categorias no peso de carcaça fria $(\mathrm{P}>0,0617)$. Resultados semelhantes foram citados por Restle et al. (2001), ao verificarem que o maior rendimento de carcaça das fêmeas mais jovens compensou o menor peso de abate dessa categoria em relação às fêmeas adultas, que apresentaram 2,18 pontos percentuais a menos do que as novilhas. Restle et al. (2001) relataram que essa diferença era devida ao maior desenvolvimento do aparelho reprodutivo das vacas em relação às novilhas e, também, ao maior arqueamento das costelas observado nas vacas, provavelmente, em função de uma adaptação do organismo para alojar o feto durante a gestação. Estudando animais cruzados Hereford x Nelore, terminados e abatidos com um ano de idade, Vaz et al. (2001a) quantificaram os órgãos internos e externos de machos castrados e fêmeas, verificando que o maior rendimento de carcaça dos machos está ligado também ao menor peso do rúmen vazio e do couro. Os mesmos autores sugerem que o maior peso do rúmen seria uma necessidade das fêmeas para atender os requerimentos nutricionais bastante elevados durante a gestação e a amamentação. Em relação ao maior peso do couro, os autores citam que seria em decorrência do maior arqueamento de costelas das fêmeas, aumentando a superfície do animal.

A espessura de gordura sobre a carcaça foi semelhante entre as duas categorias estudadas, sendo de 5,33 $\mathrm{mm}$ nos novilhos e 5,83 $\mathrm{mm}$ nas vacas. Em trabalho que estudou o efeito de sexo em animais superprecoces sobre as características de carcaça, Vaz et al. (2001b) não verificaram diferença na espessura de gordura subcutânea, que foi de $4,06 \mathrm{~mm}$ nos machos castrados e 5,07 $\mathrm{mm}$ nas novilhas.

Vaz et al. (2001b) observaram que o maior acúmulo de gordura sobre a carcaça aumentou a porcentagem de corte costilhar, constatação ratificada por Vaz (1999), que reporta correlação significativa entre a porcentagem de costilhar e a espessura de gordura subcutânea da carcaça. No presente trabalho, observa-se, mesmo sem diferença significativa, que as carcaças das vacas apresentaram numericamente $0,5 \mathrm{~mm}$ a mais de cobertura de gordura e significativamente maior peso $(\mathrm{P}<0,0022)$ e porcentagem de costilhar $(\mathrm{P}<0,0034)$ do que os novilhos. A porcentagem de costilhar pode estar regulada não somente pela deposição de gordura, mas também pelo maior arqueamento de costelas das fêmeas, conforme discutido anteriormente.

No presente trabalho não foi observada diferença estatística no peso e porcentagem dos cortes dianteiros e serrote entre os dois grupos de animais estudados. Realizando estudo com animais Charolês, Townsend et al. (1990c) verificaram $16,9 \%$ de porcentagem de costilhar em vacas de descarte e $15,0 \%$ em novilhos de 2,5 anos de idade. Utilizando animais 3/4 Charolês $1 / 4$ Nelore, Restle et al. (2000b) relatam maior percentagem de costilhar em vacas $(16,70 \%)$ do que em novilhas $(15,42 \%)$. Pesquisando animais Charolês, Restle et al. (2000c) relataram que vacas de descarte abatidas com quatro anos de idade apresentaram $50,1 \%$ de porcentagem de serrote, valor significativamente superior aos 47,5 e $47,6 \%$ observados, respectivamente, em vacas abatidas com 7 e 8 anos e vacas com nove ou mais anos de idade. Também em fêmeas Charolês, Restle et al. (2001) verificaram semelhança na porcentagem de dianteiro, porém maior porcentagem de serrote nas novilhas em relação às vacas, sendo de 49,45 e $47,23 \%$, respectivamente.

$\mathrm{Na}$ Tabela 2 estão relacionados os resultados referentes à conformação, maturidade fisiológica e medidas de desenvolvimento da carcaça. Verifica-se que os machos apresentaram conformação classificada como "boa menos" (10,33 pontos) e as fêmeas tiveram uma conformação classificada como "regular" (7,83 pontos). Analisando essa característica entre machos e fêmeas, Vaz et al. (2001b) não verificaram diferença significativa entre novilhos e novilhas superprecoces.

As vacas de descarte foram superiores $(\mathrm{P}<0,0001)$ aos novilhos no comprimento de carcaça (131,6 vs. $121,9 \mathrm{~cm})$ e perímetro de braço $(\mathrm{P}<0,0321)$, não existindo diferença significativa para as demais medidas de desenvolvimento da carcaça. Maior comprimento de carcaça em vacas de descarte, abatidas com idade média de oito anos, em relação a novilhas abatidas aos três anos de idade é citado no trabalho realizado por Restle et al. (2001).

Observou-se que, embora os novilhos tenham apresentado melhor conformação de carcaça, não foram superiores às vacas na espessura de coxão. Os trabalhos brasileiros que compararam animais jovens 
Tabela 2 - Médias de conformação, maturidade fisiológica e medidas de desenvolvimento da carcaça Table 2 - Means for conformation, maturity and growth measures of the carcasses

\begin{tabular}{|c|c|c|c|c|}
\hline $\begin{array}{l}\text { Característica } \\
\text { Characteristic }\end{array}$ & $\begin{array}{l}\text { Novilhos } \\
\text { Steers }\end{array}$ & $\begin{array}{l}\text { Vacas } \\
\text { Cows }\end{array}$ & $\begin{array}{l}\text { Erro-pradrão } \\
\text { Standard error }\end{array}$ & $\begin{array}{c}\text { Probabilidade } \\
\text { Probability }\end{array}$ \\
\hline Conformação, pontos ${ }^{1}$ & 10,33 & 7,83 & 0,28 & 0,0001 \\
\hline $\begin{array}{l}\text { Conformation, points }{ }^{I} \\
\text { Maturidade fisiológica, pontos } \\
\text { Physiologic maturity, points }\end{array}$ & 13,67 & 4,58 & 0,47 & 0,0001 \\
\hline $\begin{array}{l}\text { Comprimento de carcaça, } \mathrm{cm} \\
\text { Carcass length, } \mathrm{cm}\end{array}$ & 121,9 & 131,6 & 0,8 & 0,0001 \\
\hline $\begin{array}{l}\text { Comprimento de perna, } \mathrm{cm} \\
\text { Leg length, } \mathrm{cm}\end{array}$ & 63,46 & 62,79 & 0,61 & 0,4460 \\
\hline $\begin{array}{l}\text { Espessura de coxão, cm } \\
\text { Cushion thickness, } \mathrm{cm}\end{array}$ & 22,29 & 21,62 & 0,47 & 0,3257 \\
\hline $\begin{array}{l}\text { Comprimento de braço, } \mathrm{cm} \\
\text { Arm length, } \mathrm{cm}\end{array}$ & 37,33 & 37,08 & 0,26 & 0,5005 \\
\hline $\begin{array}{l}\text { Perímetro de braço, } \mathrm{cm} \\
\text { Arm perimeter, } \mathrm{cm}\end{array}$ & 34,67 & 33,58 & 0,33 & 0,0321 \\
\hline
\end{tabular}

${ }^{1}$ Escala variando de 1 a 18 pontos, sendo: 7 regular menos, $8=$ regular, $9=$ regular mais, $10=$ boa menos e $11=$ boa $(S c a l e$ from 1 to 18 points, being: 7 = regular,$- 8=$ regular, $9=$ regular,$+ 10=$ good,$- 11=$ good $)$.

e adultos têm verificado semelhança na espessura de coxão entre vacas jovens e adultas (Restle et al., 2000b, 2001).

Buscando analisar o efeito do sexo sobre o crescimento da carcaça, Vaz et al. (2001b) verificaram que os machos castrados foram superiores às fêmeas no comprimento de carcaça, comprimento de perna e perímetro de braço, sendo os valores de, respectivamente, 117,$3 ; 68,9$; e $33,8 \mathrm{~cm}$ nos machos e 111,6 ; 64,0 e 30,4 cm nas fêmeas. Os resultados de Junqueira et al. (1998), que estudaram machos e fêmeas abatidos aos dois anos de idade, mostram que o comprimento de carcaça foi significativamente superior nos machos (128,2 vs. 121,8 cm).

$\mathrm{Na}$ Tabela 3, são apresentados os resultados referentes à área de Longissimus dorsi e composição física da carcaça.

Verificou-se que a área de músculo Longissimus foi maior nos novilhos do que nas vacas. Estudando o efeito de sexo em animais cruzados, Junqueira et al. (1998) observaram maior área de Longissimus nos machos em relação às fêmeas. Sendo a área de Longissimus dorsi uma medida que expressa a musculosidade da carcaça (Jardim, 1988), ratifica-se a maior musculosidade da carcaça dos machos, conforme citado anteriormente, quando foram discutidos os resultados referentes à conformação de carcaças.

A porcentagem de músculo na carcaça foi superior nos novilhos $(\mathrm{P}<0,0093)$, sendo a porcentagem de gordura superior nas vacas de descarte $(\mathrm{P}<0,0339)$. Berg \& Butterfield (1976) mediram o peso de músculo e gordura de novilhos e novilhas, por dia de vida, desde o nascimento até o abate. Nesse estudo, foi verificado que os novilhos apresentavam $52 \mathrm{~g}$ a mais de crescimento muscular por dia que as novilhas, mas apenas $4 \mathrm{~g}$ a mais de crescimento do tecido adiposo. Já quando a comparação foi feita entre machos não castrados e fêmeas, os mesmos autores concluíram que as fêmeas apresentaram $134 \mathrm{~g}$ a menos de crescimento muscular, mas mostraram $24 \mathrm{~g}$ a mais de crescimento adiposo que os bovinos machos inteiros. Esses resultados mostram que pode-se esperar maior relação de músculo/gordura nos machos do que nas fêmeas.

Restle et al. (2001) verificaram que o teor de gordura não diferiu entre as duas categorias de fêmeas analisadas em seu trabalho, mas observaram que a porcentagem de osso foi maior nas vacas adultas $(15,37 \%)$ do que nas novilhas abatidas aos três anos de idade $(14,46 \%)$. Os autores atribuíram tal diferença ao fato de que os animais mais jovens possuem ossos mais finos do que animais mais velhos, comentário que é ratificado por Vaz \& Restle (1998). No presente trabalho, a similaridade entre as porcentagens de ossos verificadas nas carcaças das duas categorias estudadas pode ser atribuído ao fato de os animais mais jovens serem machos, o que compensaria o efeito da idade com o efeito de sexo.

Ao dividir a porcentagem de músculo pela percentagem de gordura da carcaça, observa-se um valor equivalente a 2,83 nos novilhos e 1,74 nas vacas de descarte $(\mathrm{P}<0,0058)$. Por outro lado, a divisão da 
Tabela 3 - Médias de área de Longissimus dorsi (ALD) e características de composição física da carcaça Table 3 - Means for Longissimus dorsi area (LDA) and carcass composition

\begin{tabular}{|c|c|c|c|c|}
\hline $\begin{array}{l}\text { Característica } \\
\text { Characteristic }\end{array}$ & $\begin{array}{l}\text { Novilhos } \\
\text { Steers }\end{array}$ & $\begin{array}{l}\text { Vacas } \\
\text { Cows }\end{array}$ & $\begin{array}{l}\text { Erro-pradrão } \\
\text { Standard error }\end{array}$ & $\begin{array}{l}\text { Probabilidade } \\
\text { Probability }\end{array}$ \\
\hline $\begin{array}{l}\mathrm{ALD}, \mathrm{cm}^{2} \\
L D A, \mathrm{~cm}^{2}\end{array}$ & 54,52 & 48,72 & 1,48 & 0,0110 \\
\hline $\begin{array}{l}\text { ALD }, \mathrm{cm}^{2} / 100 \mathrm{~kg} \text { carcaça fria } \\
L D A, \mathrm{~cm}^{2} / 100 \mathrm{~kg} \text { of cold carcass }\end{array}$ & 25,99 & 22,10 & 0,71 & 0,0009 \\
\hline $\begin{array}{l}\text { Músculo na carcaça, \% } \\
\text { Muscle, \% }\end{array}$ & 63,96 & 56,28 & 1,91 & 0,0093 \\
\hline $\begin{array}{l}\text { Gordura na carcaça, } \% \\
\text { Fat, } \%\end{array}$ & 21,08 & 25,29 & 1,32 & 0,0339 \\
\hline $\begin{array}{l}\text { Osso na carcaça, } \% \\
\text { Bone, \% }\end{array}$ & 15,23 & 17,69 & 1,22 & 0,1680 \\
\hline $\begin{array}{l}\text { Músculo/gordura } \\
\text { Muscle/fatratio }\end{array}$ & 2,83 & 1,74 & 0,25 & 0,0058 \\
\hline $\begin{array}{l}\text { Músculo/osso } \\
\text { Muscle/bone ratio }\end{array}$ & 4,22 & 3,43 & 0,21 & 0,0125 \\
\hline $\begin{array}{l}\text { Músculo + gordura/osso } \\
\text { Muscle + fat/bone ratio }\end{array}$ & 5,62 & 4,96 & 0,26 & 0,0893 \\
\hline
\end{tabular}

porcentagem de músculo pela porcentagem de osso mostra superioridade estatística para os novilhos. Vaz e Restle (1998) comentam que essas características têm fundamental importância quando se pretende aumentar a aceitação da carne bovina, já que a mesma perdeu bastante espaço na mesa dos consumidores para carnes alternativas ou mesmo para a proteína vegetal. Parte do preço da carne bovina poderia ser reduzida se existissem trabalhos de seleção no sentido de diminuir a participação relativa de osso na carcaça, e reeducação dos frigoríficos, que hoje exigem carcaças com quantidade excessiva de gordura, a qual acaba sendo descartada no momento do toalete da carcaça, ou da desossa dos cortes comerciais.

Berg \& Butterfield (1976) relatam que entre machos e fêmeas de mesma idade não são esperadas diferenças nas relações músculo/osso e músculo + gordura/osso, desde que as carcaças possuam um grau de acabamento semelhante. Essa afirmação é ratificada no trabalho de Vaz et al. (2001d), que não verificaram efeito significativo do sexo em animais superprecoces, nas características músculo/osso e músculo + gordura/osso. As diferenças nessas características começam a ser mais evidentes quando se trabalha com vacas de descarte, as quais possuem parte das perdas musculares ocorridas durante os períodos de perda de peso, recomposta por gordura intermuscular e subcutânea durante a fase de engorda, principalmente quando essa ocorre em confinamento com alto nível energético (Di Marco, 1994), conforme ocorreu no presente estudo.

$\mathrm{Na}$ Tabela 4 estão apresentados os resultados referentes à cor, textura, marmoreio da carne. Não foi observada diferença estatística para a coloração da carne, sendo de 4,67 pontos nos novilhos e 4,25 pontos nas vacas de descarte. Na sua pesquisa, Restle et al. (2001) não verificaram diferença significativa na coloração da carne, sendo de 3,47 pontos nas novilhas e 3,72 pontos nas vacas abatidas com idade média de oito anos. Vaz et al. (2001c) estudaram vacas de descarte Charolês agrupadas em quatro grupos de idade ao abate, quatro, cinco ou seis, sete ou oito e mais de oito anos de idade, observando que a coloração da carne não diferiu entre os tratamentos avaliados.

Trabalhando com novilhos de 2,5 anos e vacas de descarte das raças Charolês e Devon, Muller et al. (1984) verificaram carne de coloração mais escura nas vacas. Segundo Lawrie (1970), Arthaud et al. (1977), Boggs \& Merkel (1981) e Muller (1987), coloração da carne é uma das características que tende a acentuar-se com o avanço da idade dos animais, sendo esse fator um dos inconvenientes do abate de animais adultos. Muller (1987) comenta, ainda, que a cor da carne não afeta a palatabilidade da mesma ou seu valor organoléptico, mas é um fator importante na comercialização, tendo em vista que a carne de coloração mais escura sofre maior rejeição pelos consumidores. No presente trabalho, pode-se 
Tabela 4 - Valores médios para cor, textura e marmoreio da carne

Table 4 - Means for meat color, texture and marbling

\begin{tabular}{lcccr}
\hline $\begin{array}{l}\text { Característica } \\
\text { Characteristic }\end{array}$ & $\begin{array}{c}\text { Novilhos } \\
\text { Steers }\end{array}$ & $\begin{array}{c}\text { Vacas } \\
\text { Cows }\end{array}$ & $\begin{array}{c}\text { Erro-pradrão } \\
\text { Standard error }\end{array}$ & $\begin{array}{r}\text { Probabilidade } \\
\text { Probability }\end{array}$ \\
\hline $\begin{array}{l}\text { Cor, pontos } \\
\text { Color, points }^{1}\end{array}$ & 4,67 & 4,25 & 0,18 & 0,1232 \\
$\begin{array}{l}\text { Textura, pontos } \\
\text { Texture, points }^{2}\end{array}$ & 4,17 & 4,08 & 0,10 & 0,5575 \\
$\begin{array}{l}\text { Marmoreio, pontos } \\
\text { Marbling, points }^{3 S}\end{array}$ & 4,33 & 7,25 & 0,78 & 0,0149 \\
\hline
\end{tabular}

${ }^{1}$ Escala de 1 a 5 pontos, sendo: 1 = escura, 5 = vermelho vivo.

2 Escala de 1 a 5 pontos, sendo: $1=$ muito grosseira, $5=$ muito fina.

${ }^{3}$ Escala de 1 a 18 pontos, sendo: $6=$ leve,$+ 7=$ pequeno,$- 8=$ pequeno, $9=$ pequeno + .

1 Score from 1 to 5 points, being: $1=$ dark, $5=$ bright red.

2 Score from 1 to 5 points, being: $1=$ very coarse, $5=$ very fine.

3 Score from 1 to 18 points, being: $5=$ slight, $6=$ slight $^{+}, 7=$ small.

verificar que as vacas de descarte apresentaram carne com uma coloração que pode ser considerada como boa, valores bastante próximos aos verificados em novilhas superprecoces oriundas do cruzamento Hereford x Nelore (Vaz et al., 2001d).

Assim como a coloração, também a textura da carne foi semelhante $(\mathrm{P}>0,5575)$ entre as duas categorias avaliadas. Muller et al. (1984) observaram textura mais grosseira em vacas das raças Charolês e Devon do que em machos de 2,5 anos das mesmas raças. Restle et al. (2001) também verificaram textura mais fina nas novilhas de três anos ( 3,67 pontos) em relação às vacas de descarte abatidas com idade média de oito anos (2,89 pontos). Segundo Hammond (1959), espera-se que, à medida que avança a idade dos animais, ocorra aumento do diâmetro das fibras musculares. Pardi et al. (1993) explicam que o aumento do diâmetro das fibras musculares é devido ao fato de o tecido conjuntivo de animais jovens possuir mais reticulina e menos enlaces cruzados que o colágeno.

Townsend et al. (1990a) compararam as carcaças de novilhos abatidos com dois ou três anos de idade, concluindo que não existe diferença na textura da carne entre essas duas idades de abate. Ao compararem vacas de descarte e novilhos de 2,5 anos, Townsend et al. (1990d) também não verificaram diferença significativa na textura da carne. Nesse trabalho, os animais com idade mais avançada apresentaram textura de 2,8 pontos e os bovinos mais jovens 3,2 pontos.

Observou-se marmoreio classificado como "pequeno menos" na carne das vacas e na carne dos novilhos "leve menos" $(\mathrm{P}<0,0149)$. Estudando as raças Charolês e Devon, Muller et al. (1984) comentam que o marmoreio da carne foi classificado como "pequeno" nas vacas de descarte e "leve" nos novilhos. Em animais Charolês, Townsend et al. (1990d) observaram marmoreio similar entre novilhos e vacas, o qual foi classificado como "leve" para as duas categorias bovinas. Também com vacas Charolês, Restle et al. (2001) verificaram que o marmoreio foi maior nas vacas ("pequeno mais") do que nas novilhas ("leve mais").

As características que mensuram as quebras durante o preparo da carne mostraram que não houve diferença na quebra ao descongelamento, mas os novilhos apresentaram carne com menor perda à cocção $(\mathrm{P}<0,0379)$, o que acarretou em carne de melhor suculência. A palatabilidade da carne foi também superior nos novilhos $(\mathrm{P}<0,0032)$.

Forrest et al. (1979) comentam que também a gordura da carne influencia a suculência da mesma, concluindo que a distribuição uniforme de lipídios no músculo não somente favorece a palatabilidade da carne, mas serve como uma barreira contra a perda de suco muscular durante o cozimento. Esses autores citam a importância da cobertura de gordura sobre a carcaça como meio de proteger a mesma contra a perda de umidade durante o resfriamento.

Townsend et al. (1990b) estudaram novilhos abatidos em duas idades distintas, concluindo que os novilhos de dois anos de idade mostraram maior espessura de gordura e menor perda ao resfriamento da carcaça, sendo que essa carne tendeu a apresentar menor perda durante a cocção e maior suculência do que a carne dos novilhos abatidos com três anos de idade. Wheeler et al. (1996) e Vaz (1999) comentam que a palatabilidade da carne está positivamente 
correlacionada como a maciez e a suculência da mesma. Rocha et al. (1997) verificaram coeficiente de correlação entre suculência e palatabilidade da carne de 0,79 e entre suculência e maciez de 0,87 . Vaz (1999) trabalhou com novilhos Charolês de dois anos e constatou correlação significativa entre suculência da carne e palatabilidade, mas não verificou correlação significativa entre suculência e marmoreio da carne ou entre suculência e espessura de gordura sobre a carcaça.

No presente estudo, verificou-se que a maciez da carne foi classificada como "média" nos novilhos e como "levemente abaixo da média" nas vacas de descarte $(\mathrm{P}<0,0066)$. Já Townsend et al. (1990c) não observaram diferença na maciez da carne entre novilhos e vacas de descarte. Comparando novilhos abatidos aos dois ou três anos de idade, Townsend et al. (1990a) não verificaram diferença significativa na maciez da carne. Restle et al. (1999) revisaram vários trabalhos de pesquisa, chegando à conclusão de que a carne de animais Hereford abatidos com um ano de idade apresenta maciez média de 7,5 pontos, enquanto os animais da mesma raça, abatidos aos dois anos apresentam maciez média de 5,8 pontos. Já nos animais cruza Hereford x Nelore, a diferença é menos acentuada, ou seja, 6,6 e 5,1 pontos, citados na mesma ordem.

A força de cizalhamento da carne foi semelhante $(\mathrm{P}>0,1165)$ entre novilhos e vacas de descarte.
Estudando animais Devon e Charolês, Muller et al. (1984) verificaram valores de força de cizalhamento de 9,21 kg para vacas e 7,08 $\mathrm{kg}$ nos novilhos abatidos aos 2,5 anos de idade. Townsend et al. (1990c) também compararam vacas de descarte e novilhos, verificando valores similares para as duas características estudadas. Restle et al. (1999) citam em sua revisão que os valores médios de "Shear" para novilhos abatidos aos 24 meses de idade são de 6,9 e 8,3 kg, respectivamente, para animais da raça Hereford e cruzas Hereford x Nelore e para animais de quatorze meses, de 5,2 e 5,6 kg, citados na mesma ordem. Restle et al. (2001) observaram que, entre novilhas de três anos e vacas de descarte com idade média de oito anos ao abate, os valores de Shear foram bastante similares, sendo de 5,99 e 5,95 $\mathrm{kg}$, respectivamente.

Muller et al. (1984) e Perobelli et al. (1994) trabalharam com vacas de descarte terminadas em campo nativo e verificaram valores de Shear superiores aos do presente estudo e aos verificados por Restle et al. (2001). Os últimos autores comentam que os baixos valores observados no valor de "Shear" estão ligados à terminação dos animais em confinamento, onde existe maior contato com pessoas, no caso os tratadores, fator que viria a minimizar o estresse pré-abate, acarretando em carne mais macia e menos propensa a encurtamento pelo frio.

Tabela 5 - Médias de quebras ao descongelamento e à cocção, características sensoriais e força de cizalhamento para cortar as fibras (Shear) da carne

Table 5 - Means for meat thawing and cooking losses, sensorial characteristic and Shear value

\begin{tabular}{|c|c|c|c|c|}
\hline $\begin{array}{l}\text { Característica } \\
\text { Characteristic }\end{array}$ & $\begin{array}{l}\text { Novilhos } \\
\text { Steers }\end{array}$ & $\begin{array}{l}\text { Vacas } \\
\text { Cows }\end{array}$ & $\begin{array}{l}\text { Erro-pradrão } \\
\text { Standard error }\end{array}$ & $\begin{array}{l}\text { Probabilidade } \\
\text { Probability }\end{array}$ \\
\hline $\begin{array}{l}\text { Quebra ao descongelamento, \% } \\
\text { Thawing loss, \% }\end{array}$ & 3,90 & 4,59 & 0,54 & 0,3768 \\
\hline $\begin{array}{l}\text { Quebra ao cozimento, } \% \\
\text { Cooking loss, \% }\end{array}$ & 31,55 & 33,94 & 0,77 & 0,0379 \\
\hline $\begin{array}{l}\text { Palatabilidade, pontos }{ }^{1} \\
\text { Flavor points }{ }^{1}\end{array}$ & 5,60 & 4,83 & 0,13 & 0,0003 \\
\hline $\begin{array}{l}\text { Suculência, pontos }{ }^{1} \\
\text { Juiciness points }\end{array}$ & 5,45 & 4,70 & 0,16 & 0,0032 \\
\hline $\begin{array}{l}\text { Maciez, pontos }{ }^{1} \\
\text { Tenderness, points }\end{array}$ & 5,15 & 4,12 & 0,24 & 0,0066 \\
\hline $\begin{array}{l}\text { Shear, kg } \\
\text { Shear, } \mathrm{kg}\end{array}$ & 6,01 & 7,51 & 0,65 & 0,1165 \\
\hline
\end{tabular}

${ }^{1}$ Escala de 1 a 9 pontos, sendo: 1 = sem sabor, sem suculência e extremamente dura e 9 = extremamente saborosa, extremamente suculenta e extremamente macia.

${ }^{1}$ Score from 1 to 9 points, being: 1 = 1 = extremely tough, extremely dry, extremely undesirable; 9 = extremely tender, extremely juicy, extremely flavorful. 


\section{Conclusões}

Vacas de descarte Hereford apresentaram maior peso de abate e carcaças mais compridas do que novilhos da mesma raça, que apresentaram maior rendimento de carcaça.

Vacas de descarte Hereford apresentaram maior porcentagem de costilhar do que novilhos da mesma raça.

Na raça Hereford, novilhos de dois anos de idade apresentaram carne de menor perda ao cozimento, melhor palatabilidade, suculência e maciez, mas não diferiram de vacas de descarte na força de cizalhamento para romper as fibras da carne.

\section{Literatura Citada}

ANUALPEC. Anuário da pecuária brasileira. São Paulo: Editora Argos, 2000. 392p.

ARTHAUD, V.H.; MANDIGO, R.W.; KOCH, R.M. et al. Carcass composition, quality and palatability attributes of bulls and steers feed different energy levels and killed at four ages. Journal of Animal Science, v.44, n.1, p.53-64, 1977.

BERG, R.T.; BUTTERFIELD, R.M. New concepts of cattle growth. Sydney: Sydney University Press, 1976. 240p.

BoGGS, D.L.; MERKEL, R.A. Live animal: Carcass evaluation and selection manual. Iowa: Michigan State University, 1981. 199p.

DEL DUCA, L.O.; MORAES, C.O.C.; SALOMONI, E. Efeito do peso de abate nas características quantitativas da carcaça de novilhos Ibagé. In: REUNIÃO ANUAL DA SOCIEDADE BRASILEIRA DE ZOOTECNIA, 36., 1999, Porto Alegre, Anais... Porto Alegre: Sociedade Brasileira de Zootecnia, 1999. p.357.

DI MARCO, O.N. Crecimiento y respuesta animal. Balcarce: AAPA, 1994. 129p.

FORREST, J.C.; ABERLE, E.D.; HEDRICK, H.B. et al. Fundamentos de ciencia de la carne. Zaragoza: Acribia, 1979. 342p.

HAMMOND, J. Avances en fisiologia zootecnica. v.1. Zaragoza: Acribia, 1959. 432p.

HANKINS, O.G.; HOWE, P.E. Estimation of the composition of beef carcasses and cuts. Washington: United States Department of Agriculture, 1946 (Technical Bulletin, 926).

JARDIM, P.O.C.; ZIEGLER, J.C.; OSÓRIO, J.C.S. Efeito da raça e da idade sobre o peso da carcaça e o peso e percentagem dos principais cortes em novilhos. Revista da Sociedade Brasileira de Zootecnia, v.12, n.3, p.551-561, 1988.

JUNQUEIRA, J.O.B.; VELLOSO, L.; FELÍCIO, P.E. Desempenho, rendimentos de carcaça e cortes de animais, machos e fêmeas, mestiços Marchigiana x Nelore, terminados em confinamento. Revista da Sociedade Brasileira de Zootecnia, v.27, n.6, p.1199-1205, 1998.

LAWRIE, R.A. Ciência de la carne. Zaragoza: Acribia, 1970. $342 p$.

MULLER, L.; GRASSI, C.; RESTLE, J. Comparação da qualidade da carcaça proveniente de novilhos e vacas. In: REUNIÃO ANUAL DA SOCIEDADE BRASILEIRA DE ZOOTECNIA, 21., 1984, Belo Horizonte. Anais... Viçosa, MG: Sociedade Brasileira de Zootecnia, 1984. p.107.

MULLER, L. Normas para avaliação de carcaça e concurso de carcaças de novilhos. 2.ed. Santa Maria: Universidade Federal de Santa Maria, 1987. 31p.

PARDI, M.C.; SANTOS, I.F.; SOUZA, E.R. et al. Ciência, higiene e tecnologia da carne. Goiânia: Universidade Federal de Goiás, 1993. v.1, 587p.

PEROBELLI, Z.V.; RESTLE, J.; MULLER, L. Estudo das carcaças de vacas de descarte das raças Charolês e Nelore. Pesquisa Agropecuária Brasileira, v.30, n.3, p.409-412, 1994.

RESTLE, J.; BRONDANI, I.L.; BERNARDES, R.A.L.C. O novilho superprecoce. In: RESTLE, J. (Ed.) Confinamento, pastagens e suplementação para produção de bovinos de corte. Santa Maria: Universidade Federal de Santa Maria, 1999. p.191-214.

RESTle, J.; ROSO, C.; OlIVEIRA, A. N. et al. 2000a. Suplementação energética para vacas de descarte de diferentes idades em terminação em pastagem cultivada de estação fria sob pastejo horário. Revista da Sociedade Brasileira de Zootecnia, v.29, n.4, p.1216-1222, 2000a.

RESTLE, J.; VAZ, F.N.; PASCOAL, L.L. et al. Aspectos quantitativos da carcaça de novilhas ou vacas de descarte 3/4 Charolês 1/4 Nelore, terminadas em confinamento. In: REUNIÃO ANUAL DA SOCIEDADE BRASILEIRA DE ZOOTECNIA, 37., 2000, Viçosa, MG. Anais... Viçosa: Sociedade Brasileira de Zootecnia, 2000b. p.143.

RESTLE, J.; VAZ, F.N.; PASCOAL, L.L. et al. Características de carcaça de vacas de diferentes idades, terminadas em pastagem cultivada de estação fria sob pastejo horário mais suplementação. In: REUNIÃO ANUAL DA SOCIEDADE BRASILEIRA DE ZOOTECNIA, 37., 2000, Viçosa, MG. Anais... Viçosa, MG: Sociedade Brasileira de Zootecnia, 2000c. p. 146.

RESTLE, J.; CERDÓTES, L.; VAZ, F.N. et al. Características da carcaça e da carne de novilhas e vacas de descarte Charolês, terminadas em confinamento. Revista Brasileira de Zootecnia. v.30, n.3, p.1065-1073, 2001.

ROCHA, J.B.T.; PEROTTONI, J.; RESTLE, J. et al. Qualidade da carne de animais inteiros de dois grupos genéticos, abatidos aos quatorze meses de idade. In: REUNIÃO ANUAL DA SOCIEDADE BRASILEIRA DE ZOOTECNIA, 34., 1997, Juiz de Fora. Anais... Juiz de Fora: Sociedade Brasileira de Zootecnia, 1997. p.199-201.

STATISTICAL ANALYSIS SYSTEM - SAS. Language reference. Version 6, SAS Institute Inc., Cary: 1990. 1042p.

TOWNSEND, M.R.; RESTLE, J.; MULLER, L. Avaliação qualitativa de carcaças de novilhos com diferentes idades confinados por dois invernos subseqüentes. In: REUNIÃO ANUAL DA SOCIEDADE BRASILEIRA DE ZOOTECNIA, 27., 1990. Campinas. Anais... Piracicaba: Fundação de Estudos Agrários "Luiz de Queiroz", 1990a. p.359.

TOWNSEND, M.R.; RESTLE, J.; MULLER, L. Avaliação quantitativa de carcaças de novilhos com diferentes idades confinados por dois invernos subsequentes. In: REUNIÃO ANUAL DA SOCIEDADE BRASILEIRA DE ZOOTECNIA, 27., 1990, Campinas. Anais... Piracicaba: Fundação de Estudos Agrários "Luiz de Queiroz", 1990b. p.360.

TOWNSEND, M.R.; RESTLE, J.; PASCOAL, L.L. et al. Avaliação quantitativa das carcaças de novilhos e vacas terminadas em confinamento. In: REUNIÃO ANUAL DA SOCIEDADE BRASILEIRA DE ZOOTECNIA, 27., 1990, Campinas. Anais... Piracicaba: Fundação de Estudos Agrários "Luiz de Queiroz", 1990c. p.362.

TOWNSEND, M.R.; RESTLE, J.; PASCOAL, L.L. et al. Carac-

R. Bras. Zootec., v.31, n.3, p.1501-1510, 2002 (suplemento) 
terísticas qualitativas das carcaças de novilhos e vacas terminadas em confinamento. In: REUNIÃO ANUAL DA SOCIEDADE BRASILEIRA DE ZOOTECNIA, 27., 1990, Campinas. Anais... Piracicaba: Fundação de Estudos Agrários "Luiz de Queiroz", 1990d. p.361.

VAZ, F.N. Cruzamento alternado das raças Charolês e Nelore: características de carcaça e da carne de novilhos abatidos aos dois anos. Santa Maria, RS: UFSM, 1999. 58p. Dissertação (Mestrado em Zootecnia) - Universidade Federal de Santa Maria, 1999.

VAZ, F.N.; RESTLE, J. Produção de carne com qualidade. In: RESTLE, J.; BRONDANI, I.L.; PASCOAL, L.L. et al. (Eds.) Produção intensiva com qualidade em bovinos de corte. Santa Maria: Universidade Federal de Santa Maria, 1998. p.104-119.

VAZ, F.N.; RESTLE, J.; ALVES FILHO, D.C. et al. Peso das vísceras e rendimento de carcaças de novilhos ou novilhas Braford superprecoces, terminados com suplementação em pastagem cultivada com pastejo controlado. In: REUNIÃO ANUAL DA SOCIEDADE BRASILEIRA DE ZOOTECNIA, 38., 2001, Piracicaba. Anais... Piracicaba: Fundação de Estudos Agrários "Luiz de Queiroz”, 2001a. p.1531-1532.

VAZ, F.N.; RESTLE, J.; BRONDANI, I.L. et al. Características de carcaça de novilhos ou novilhas Braford superprecoces, terminados com suplementação em pastagem cultivada com pastejo controlado. In: REUNIÃO ANUAL DA SOCIEDADE BRASILEIRA DE ZOOTECNIA, 38., 2001, Piracicaba. Anais... Piracicaba: Fundação de Estudos Agrários "Luiz de Queiroz", 2001b. p.1534-1535.
VAZ, F.N.; RESTLE, J.; BERNARDES, R.A.L.C. et al. Efeito da idade ao abate sobre a qualidade da carcaça e da carne de vacas Charolês, terminadas com suplementação em pastagem cultivada de estação fria. In: REUNIÃO ANUAL DA SOCIEDADE BRASILEIRA DE ZOOTECNIA, 38., 2001, Piracicaba. Anais... Piracicaba: Fundação de Estudos Agrários "Luiz de Queiroz", 2001c. p.1535-1537.

VAZ, F.N.; RESTLE, J.; CERDÓTES, L. et al. Características qualitativas das carcaças e da carne de novilhos ou novilhas Braford superprecoces, terminados com suplementação em pastagem cultivada com pastejo controlado. In: REUNIÃO ANUAL DA SOCIEDADE BRASILEIRA DE ZOOTECNIA, 38., 2001, Piracicaba. Anais... Piracicaba: Fundação de Estudos Agrários "Luiz de Queiroz", 2001d. p.1532-1534.

WHEELER, T.L.; CUNDIFF, L.V.; KOCH, R.M. Characterization of biological types of cattle (Cycle IV): carcass traits and longissimus palatability. Journal of Animal Science, v.74, n.5, p.1023-1035, 1996. 